\title{
Hypophysitis Presenting With Atypical Rapid Deterioration: With Special Reference to Immunoglobulin G4-Related Disease
}

\author{
-Case Report-
}

\author{
Shinichiro Osawa, Yoshikazu OGawA, \\ Mika WATANABE*, and Teiji TOMINAGA** \\ Department of Neurosurgery, Kohnan Hospital, Sendai, Miyagi; \\ Departments of *Pathology and ** Neurosurgery, \\ Tohoku University Graduate School of Medicine, Sendai, Miyagi
}

\begin{abstract}
Primary hypophysitis is believed to be a chronic inflammation of the pituitary tissue caused by the autoimmune mechanism. The disease can be classified based on morphology and histology simultaneously, but the relationships between these subtypes remain unclarified. Moreover, hypophysitis may occur as a part of systemic immunoglobulin G4 (IgG4)-related plasmacytic disease. A 74-year-old woman was initially diagnosed with infundibulo-hypophysitis. After a long period of stability, she suffered rapid deterioration with evolving endocrinopathies and visual symptoms. Biopsy specimen established the diagnosis as granulomatous hypophysitis with positive reaction for IgG4 in infiltrating plasma cells. Postoperative glucocorticoid administration improved her condition dramatically. This case illustrates two interesting points: The rapid deterioration after a long stable clinical course, and the presence of IgG4-positive tissue in the pituitary gland, which can be considered as "primary" hypophysitis with no systemic IgG4-related disease in other organs.
\end{abstract}

Key words: granulomatous hypophysitis, immunoglobulin G4, rapid deterioration, systemic immunoglobulin G4-related plasmacytic disease

\section{Introduction}

Primary hypophysitis is believed to be a chronic inflammation of the pituitary tissue caused by the autoimmune system, with an incidence of only 1/9,000,000/year. ${ }^{2)}$ Diagnosis is based on the findings of magnetic resonance (MR) imaging, endocrinological assessment, immunological markers, and other clinical features. The disease can be classified into subtypes based on the morphology, such as location and/or endocrinological behavior, into adenohypophysitis, infundibulo-neurohypophysitis (INH), and panhypophysitis $(\mathrm{PH})$, or based on the histological findings into lymphocytic hypophysitis, granulomatous hypophysitis, ${ }^{1,6,9,10)}$ and xanthomatous hypophysitis. ${ }^{3)}$ However, a few exceptional cases could not be assigned by either morphological or histological classification. ${ }^{6)}$ Therefore, the relationships between these two classifications need to be clarified. Recently, systemic immunoglobulin G4 (IgG4)-related plasmacytic disease (SIPD) has provoked keen interest in modern immunology, because of the relationship to autoimmune inflammation of multiple organs such as pancreatitis, sailvary glanditis,

Received March 12, 2009;

Accepted April 28, 2009 tubulointerstitial nephritis, retroperitoneal fibrosis, and hypophysitis. ${ }^{8,11-14)}$ However, hypophysitis has been histologically confirmed as a part of SIPD in only one case, because of difficulty in confirming the pathology of the pituitary gland,11) and IgG4-positive hypophysitis has never been found as the "primary" hypophysitis with any other organ disorder of SIPD.

Here we report a case of primary hypophysitis with rapid deterioration of the pituitary mass after remaining stable for 28 months, which was initially identified as $\mathrm{INH}$, then as $\mathrm{PH}$, and the final histological diagnosis was granulomatous hypophysitis with abundant IgG4-positive plasma cells.

\section{Case Presentation}

A 74-year-old woman presented with severe thirst and easy fatigability at the outpatient department of a general hospital. No diagnosis could be established, so she was treated for suspected depression not by endocrinology but symptomatologically at the Department of Psychosomatic Medicine of Tohoku University. Although anterior pituitary function was preserved (Table 1), she was suffering from the central type of diabetes insipidus, and was treat- 
Table 1 Endocrinological findings

\begin{tabular}{|c|c|c|c|c|c|c|}
\hline & June 2005 & January 2008 (basal) & $15 \mathrm{~min}$ & $30 \mathrm{~min}$ & $60 \mathrm{~min}$ & $90 \mathrm{~min}$ \\
\hline $\mathrm{TSH}(\mu \mathrm{IU} / \mathrm{ml})$ & 0.67 & $0.04 \downarrow$ & 0.059 & 0.084 & 0.090 & 0.085 \\
\hline Free T4 (ng/ml) & 1.22 & 0.78 & & & & \\
\hline Free T3 $(\mathrm{pg} / \mathrm{ml})$ & 2.02 & 2.00 & & & & \\
\hline FSH (mIU/ml) & 23.7 & $1.69 \downarrow$ & 2.04 & 0.80 & 4.00 & 5.21 \\
\hline $\mathrm{LH}(\mathrm{mIU} / \mathrm{ml})$ & 9.22 & $0.07 \downarrow$ & 0.10 & 0.21 & 0.34 & 0.40 \\
\hline ACTH (pg/dl) & 22.0 & 8.6 & 249.0 & 327.0 & 345.0 & 456.0 \\
\hline Serum cortisol $(\mu \mathrm{g} / \mathrm{dl})$ & 16.0 & $1.0 \downarrow$ & 4.63 & 7.37 & 9.94 & 12.21 \\
\hline PRL (ng/ml) & 16.7 & 39.6 & 89.50 & 77.95 & 64.25 & 60.99 \\
\hline $\mathrm{GH}(\mathrm{ng} / \mathrm{ml})$ & 0.6 & 0.67 & & & & \\
\hline somatomedin C (ng/ml) & 85.0 & $76.2 \downarrow$ & & & & \\
\hline
\end{tabular}

ACTH: adrenocorticotropic hormone, FSH: follicle-stimulating hormone, GH: growth hormone, LH: luteinizing hormone, PRL: prolactin, TSH: thyroid-stimulating hormone. $\downarrow$ indicates below the normal range. Stimulation test using $200 \mu \mathrm{g}$ thyroid-releasing hormone and $100 \mu \mathrm{g}$ LH-releasing hormone showed no response of TSH, LH, and FSH. Stimulation with $100 \mu$ g corticotropin-releasing hormone showed excessive and delayed response, which indicates hypothalamo-pituitary-adrenal insufficiency.

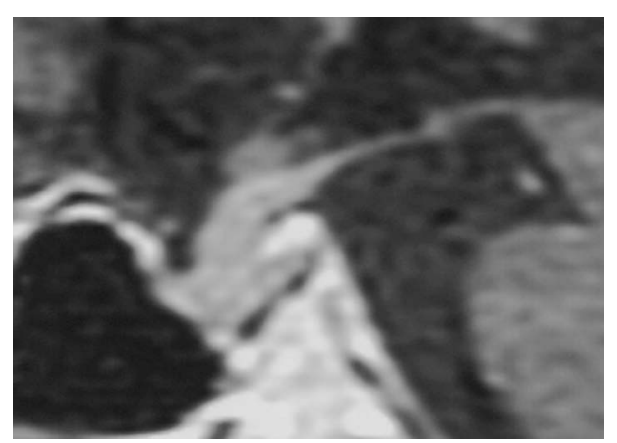

Fig. 1 Sagittal $T_{1}$-weighted magnetic resonance image with gadolinium revealing the swollen pituitary infundibulum, whereas the anterior pituitary gland was within the normal size in September 2005. The pituitary gland is $16 \times 10 \times 13 \mathrm{~mm}$.

ed with desmopressin acetate (DDAVP). Her condition improved. However, MR imaging showed swelling of the pituitary infundibulum (Fig. 1), so she was referred to our outpatient department in September 2005.

Metastatic tumor and sarcoidosis were considered as diagnoses, but all serum tumor markers and inflammatory markers were within the normal ranges, and systemic gallium scintigraphy detected no abnormal accumulation. Therefore, primary tumor in the posterior pituitary gland or INH was suspected. Supplementation of DDAVP therapy was continued with close follow up using MR imaging and serum marker measurements. Her good condition remained stable and MR imaging showed no changes until October 2007. However, she rapidly became delirious and was urgently transferred to the Department of Psychosomatic Medicine of Tohoku University in December 2007. Blood examination revealed hypernatremia $(152 \mathrm{mEq} / \mathrm{l})$, and severe deterioration of pituitary function. MR imaging showed that both the pituitary infundibulum and the anterior pituitary gland were significantly swollen, and the optic chiasm was displaced upwards (Fig. 2). Hypocortisolemia caused by hypopituitarism was thought to have induced the serum electrolyte disorder, so she was treated

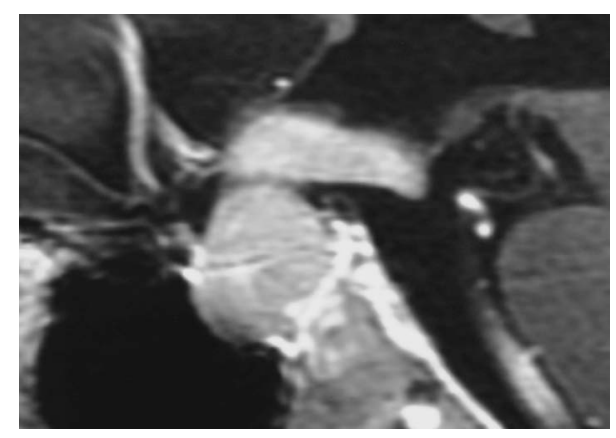

Fig. 2 Sagittal $\mathrm{T}_{1}$-weighted magnetic resonance image with gadolinium revealing the involvement of the pituitary gland in December 2007. The pituitary gland is $21 \times 17 \times 19 \mathrm{~mm}$.

with daily oral intake of $10 \mathrm{mg}$ hydrocortisone as a routine supplementation. She recovered consciousness and was transferred to our department in January 2008 for biopsy to confirm the diagnosis.

On admission, no enlargement of the salivary or lacrimal glands was seen, and renal, hepatic, and pancreatic enzymes were within the normal ranges. Her consciousness was clear, but visual acuity of the left eye had decreased to 0.3 , and left temporal hemianopsia was detected. Endocrinological examination showed severe disturbance of the four axes of the anterior pituitary hormones except for prolactin (Table 1). Subsequent MR imaging showed no improvement of the swollen pituitary mass. Transsphenoidal surgery was performed in January 2008. Intraoperative observation found the bony structure of the sellar bottom was thinned, and the normal tissue of the anterior pituitary gland was edematous. Slightly hard gray tissue was found at the posterior portion of the sella, suggesting degenerated and fibrous posterior pituitary gland. Histological examination of the biopsy specimen showed atrophic pituitary tissue with massive infiltration of inflammatory cells including abundant plasma cells, but no indications of other adenoma-like change or malignant tumor. Immunohistochemistry for $\kappa$ and $\lambda$ light 


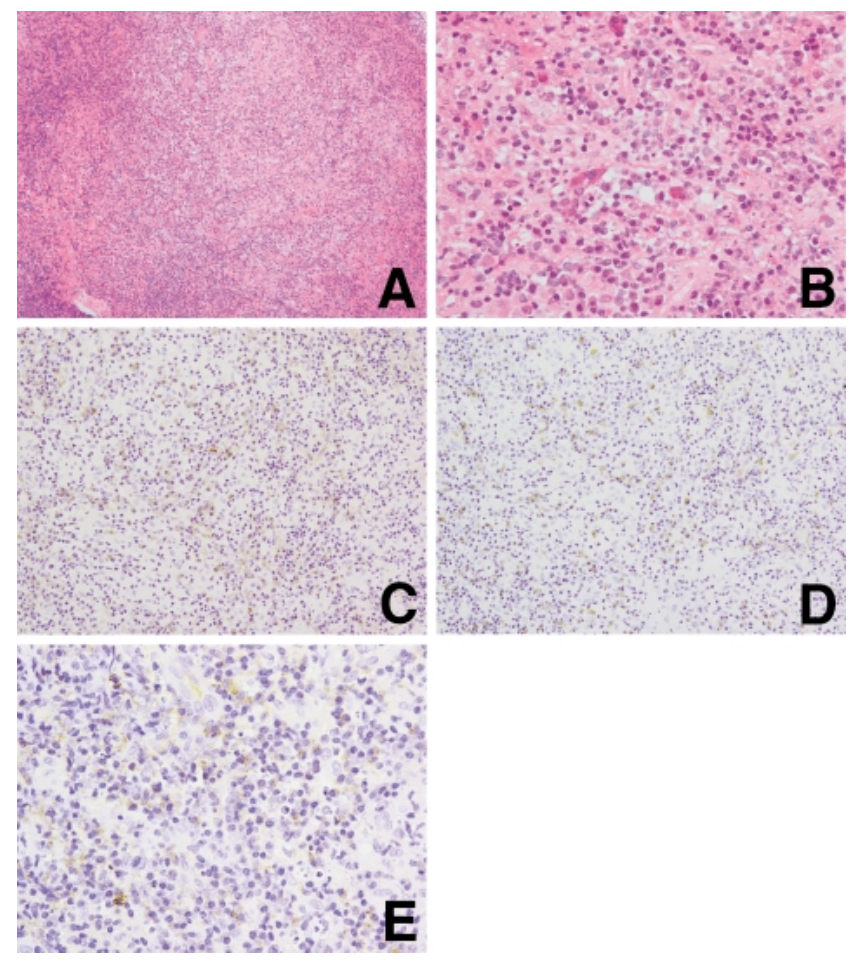

Fig. 3 A, B: Photomicrographs of the surgical specimen showing atrophic pituitary tissue with massive infiltration of plasma cells. Hematoxylin and eosin staining, original magnification $\times 80$ (A) and $\times 200$ (B). C: Photomicrograph of the surgical specimen showing significant $\boldsymbol{\kappa}$ light chain-positive cell infiltration around the pituitary tissue. Original magnification $\times 200$. D: Photomicrograph of the surgical specimen showing significant $\lambda$ light chain-positive cell infiltration around the pituitary tissue. Original magnification $\times 200$. E: Photomicrograph of the surgical specimen showing significant immunoglobulin G4-positive cell infiltration around the pituitary tissue. Original magnification $\times 200$.

chains showed no restriction and IgG4 was moderately positive in the cytoplasm of the invaded plasma cells (Fig. 3).

Pulse dose of hydrocortisone as an anti-inflammatory therapy was started from the day of surgery, using intravenous $200 \mathrm{mg}$ hydrocortisone initially and tapered daily to $30 \mathrm{mg}$ at 10 days after the operation, and then changed to $0.5 \mathrm{mg}$ dexamethasone daily. MR imaging at this point showed remarkable shrinkage of both the anterior pituitary gland and the infundibulum. She was discharged on foot while receiving $0.5 \mathrm{mg}$ dexamethasone daily. She has since remained in good condition for 15 months with $2 \mathrm{mg}$ triamcinolone daily. Normal serum IgG4 concentration ( $115 \mathrm{mg} / \mathrm{dl})$ has been maintained, and the size of the pituitary gland has remained within the normal range.

\section{Discussion}

The present case was initially classified as INH based on the MR imaging and endocrinological findings, then as
$\mathrm{PH}$, and finally as granulomatous hypophysitis based on the histological findings. This case illustrates two interesting points. First, rapid deterioration occurred after a long stable course. Such rapid deterioration and transformation has never been described in reported cases of hypophysitis. Whether lymphocytic and granulomatous hypophysitis are different diseases or simply various aspects of the same disease remains unclear, ${ }^{2,4)}$ and granulomatous hypophysitis may be a later stage of lymphocytic hypophysitis. ${ }^{7}$ Primary hypophysitis is thought to follow a chronic course, but few reports describe the long-term outcome. ${ }^{2)}$ Second, although the case was diagnosed as "primary" hypophysitis by systemic morphological examination and endocrinology, the tissue was positive for IgG4 by immunohistochemistry. Histologically confirmed hypophysitis is extremely rare as a part of SIPD. Only a single case was reported. ${ }^{11)}$ However, this patient had no past history of involvement of other organs as SIPD, and negative gallium scintigraphy, so this disease may recur and affect different organ systems. Three of 40 SIPD patients suffered recurrence during follow up for 16 years. ${ }^{12)}$ Therefore, careful systemic follow up is essential. The usefulness of measuring serum IgG4 concentration in the monitoring of SIPD is unclear, ${ }^{12)}$ but potentially reflects the degree of this inflammation.

Simple observation is generally recommended if the disease is asymptomatic. However, medication with glucocorticoid and/or surgical resection should be considered if the disease is symptomatic. ${ }^{1,5)}$ Medication with glucocorticoid is the first choice of therapy in the absence of visual disturbance requiring urgent surgical decompression. ${ }^{2}$ Our patient was receiving $10 \mathrm{mg}$ hydrocortisone daily at the time of rapid deterioration. We administered $200 \mathrm{mg}$ hydrocortisone daily after the surgery, which was tapered to $0.5 \mathrm{mg}$ dexamethasone, and observed remarkable mass reduction. The latter dosage is better for introductory therapy. In addition, monitoring of serum IgG4 concentration may allow control of the adverse effects of glucocorticoid. Surgical resection should be considered if glucocorticoid therapy is ineffective. ${ }^{1,5)}$

We report a case of granulomatous hypophysitis underwent rapid deterioration after a long stable clinical course. Immunohistochemistry revealed positive reaction for IgG4, which could indicate a part of SIPD. This case illustrates the complex nature of hypophysitis.

\section{References}

1) Buxton N, Robertson I: Lymphocytic and granulocytic hypophysitis: a single centre experience. Br J Neurosurg 15: 242-246, 2001

2) Caturegli P, Newschaffer C, Olivi A, Pomper MG, Burger PC, Rose NR: Autoimmune hypophysitis. Endocr Rev 26: 599-614, 2005

3) Folkerth RD, Price DL Jr, Schwartz M, Black PM, De Girolami U: Xanthomatous hypophysitis. Am J Surg Pathol 22: 736-741, 1998

4) Gutenberg A, Buslei R, Fahlbusch R, Buchfelder M, Brück W: Immunopathology of primary hypophysitis: implications for pathogenesis. Am J Surg Pathol 29: 329-338, 2005

5) Leung GK, Lopes MB, Thorner MO, Vance ML, Laws ER Jr: 
Primary hypophysitis: a single-center experience in 16 cases. J Neurosurg 101: 262-271, 2004

6) McKeel DW: Common histopathologic and ultrastructural features in granulomatous and lymphoid adenohypophysitis. Endocrinology 112(Suppl): 190, 1983

7) McKeel DW: Primary hypothyroidism and hypopituitarism in a young woman: pathological discussion. Am J Med 77: 326-329, 1984

8) Tanabe T, Tsushima K, Yasuo M, Urushihata K, Hanaoka M, Koizumi T, Fujimoto K, Kubo K, Uehara T, Shigematsu S, Hamano H, Kawa S: IgG4-associated multifocal systemic fibrosis complicating sclerosing sialadenitis, hypophysitis, and retroperitoneal fibrosis, but lacking pancreatic involvement. Intern Med 45: 1243-1247, 2006

9) Taylon C, Duff TA: Giant cell granuloma involving the pituitary gland. Case report. J Neurosurg 52: 584-587, 1980

10) Unlu E, Puyan FO, Bilgi S, Kemal Hamamcioglu M: Granulomatous hypophysitis: presentation and MRI appearance. J Clin Neurosci 13: 1062-1066, 2006

11) Wong S, Lam WY, Wong WK, Lee KC: Hypophysitis presented as inflammatory pseudotumor in immunoglobulin G4- related systemic disease. Hum Pathol 38: 1720-1723, 2007

12) Yamamoto $M$, Takahashi $H$, Naishiro $Y$, Isshiki $H$, Ohara $M$, Suzuki C, Yamamoto H, Kokai Y, Himi T, Imai K, Shinomura Y: Mikulicz's disease and systemic IgG4-related plasmacytic syndrome (SIPS). Nihon Rinsho Meneki Gakkai Kaishi 31: 1-8, 2008

13) Yamamoto $M$, Takahashi $H$, Ohara M, Suzuki C, Naishiro $Y$, Yamamoto H, Shinomura Y, Imai K: A case of Mikulicz's disease (IgG4-related plasmacytic disease) complicated by autoimmune hypophysitis. Scand J Rheumatol 35: 410-411, 2006

14) Yamamoto $M$, Takahashi $H$, Ohara M, Suzuki $C$, Naishiro $Y$, Yamamoto H, Shinomura Y, Imai K: A new conceptualization for Mikulicz's disease as an IgG4-related plasmacytic disease. Mod Rheumatol 16: 335-340, 2006

Address reprint requests to: Yoshikazu Ogawa, M.D., Department of Neurosurgery, Kohnan Hospital, 4-20-1 Nagamachiminami, Taihaku-ku, Sendai, Miyagi 982-8523, Japan. e-mail: yogawa@kohnan-sendai.or.jp 